\title{
Evaluation of serum lactate dehydrogenase in hypertensive disorders of pregnancy and its comparison with normal pregnancy
}

\author{
Anil Kumar ${ }^{1 *}$, Kushla Pathania², Meenakshi Kandoria ${ }^{2}$
}

\begin{abstract}
${ }^{1}$ Department of Obstetrics and Gynecology, Shri Lal Bahadur Shastri Medical College, Mandi at Ner Chowk, Himachal Pradesh, India

${ }^{2}$ Department of Obstetrics and Gynecology, Kamala Nehru State Hospital, for Mother and Child, Indira Gandhi Medical College, Shimla, Himachal Pradesh, India
\end{abstract}

Received: 23 May 2020

Revised: 08 June 2020

Accepted: 03 July 2020

\section{*Correspondence:}

Dr. Anil Kumar,

E-mail: anilkumar240274@gmail.com

Copyright: () the author(s), publisher and licensee Medip Academy. This is an open-access article distributed under the terms of the Creative Commons Attribution Non-Commercial License, which permits unrestricted non-commercial use, distribution, and reproduction in any medium, provided the original work is properly cited.

\begin{abstract}
Background: Hypertensive disorders of pregnancy and their complications rank as one of the major causes of maternal morbidity and mortality. The objective of the study was to compare the level of serum LDH in normotensive and hypertensive pregnant women and to correlate the levels with maternal and foetal outcome.

Methods: Study was conducted in department of obstetrics and gynecology Kamla Nehru State Hospital for Mother and Child, Indira Gandhi Medical College, Shimla w.e.f. $15^{\text {th }}$ July, 2014 to $14^{\text {th }}$ July, 2015. Pregnant women enrolled in the study were divided into following groups: - Group 1- Age and parity matched 202 normotensive pregnant women. Group 2- 202 women with hypertensive disorders of pregnancy as per the inclusion and exclusion criteria. Subjects were also divided according to the serum LDH levels into following groups: LDH <600 IU/L, LDH-600-800 IU/L and LDH $>800 I U / L$. The maternal and foetal outcome was correlated with the serum level of LDH. One-way analysis of variance (ANOVA) and the chi-square test were used to compare the results. Differences were considered significant when $\mathrm{p}<0.05$.

Results: Severely preeclamptic and eclamptic patients were significantly younger, with low gravidity and parity. The symptoms and complications of preeclampsia and eclampsia along with perinatal mortality were increased significantly in patients with $\mathrm{LDH}>800 \mathrm{IU} / \mathrm{L}$ as compared with those who had lower levels.

Conclusions: Lactate dehydrogenase is a useful biochemical marker that reflects the severity of and the occurrence of complications of preeclampsia and eclampsia. Identification of high-risk patients with elevated levels of lactic dehydrogenase, their close monitoring, and prompt, correct management may prevent these complications, with a subsequent decrease in maternal foetal morbidity and mortality.
\end{abstract}

Keywords: Complications, Eclampsia symptoms, Lactate dehydrogenase, Pre-eclampsia

\section{INTRODUCTION}

Hypertensive disorders of pregnancy and their complications rank as one of the major causes of maternal morbidity and mortality in the world. $^{1}$ It accounts for approximately a quarter of all antenatal admissions. $^{2}$ It includes a wide spectrum of condition, including gestational hypertension, preeclampsia and eclampsia, preeclampsia superimposed on chronic hypertension and chronic hypertension ${ }^{3}$.

Preeclampsia and eclampsia are associated with substantial risks for the fetus. These include intrauterine growth restriction, prematurity and death whereas the mother is at risk of renal failure, pulmonary edema, stroke and death. ${ }^{4}$ 
Lactate dehydrogenase is a useful biochemical marker that reflects the severity and occurrence of complications in preeclampsia. ${ }^{3}$ Lactate dehydrogenase (LDH) is mainly an intracellular enzyme. It is responsible for inter conversion of pyruvate and lactate in the cells. Its levels are several times greater inside the cells than in the plasma. Its levels are increased in the scenario of increased cell leakiness, hemolysis and cell death. ${ }^{2}$ Hence serum LDH levels can be used to assess the extent of cellular death and thereby the severity of disease.

Normal level of serum lactate dehydrogenase in nonpregnant women is $115-211 \mathrm{U} / \mathrm{L}$. During $1^{\text {st }}, 2^{\text {nd }}$ and $3^{\text {rd }}$ trimester the normal LDH levels are 78-433 U/L, 80-477 $\mathrm{U} / \mathrm{L}$ and $82-524 \mathrm{U} / \mathrm{L}$ respectively. ${ }^{5}$

The objective of the study was to compare the level of serum LDH in normotensive and hypertensive pregnant women and to correlate the levels with maternal and fetal outcome. Hence serum LDH Levels can be further used as help in making decision, regarding the management strategies to improve the maternal and fetal outcome.

\section{METHODS}

This prospective case control study was conducted in department of obstetrics and gynecology Kamla Nehru State Hospital for Mother and Child, Indira Gandhi Medical College, Shimla w.e.f. $15^{\text {th }}$ July, 2014 to $14^{\text {th }}$ July, 2015. Pregnant women enrolled in the study were divided into following groups: Group 1- age and parity matched 202 normotensive pregnant women (controls). Group 2- 202 women with hypertensive disorders of pregnancy as per the inclusion and exclusion criteria (study group). Group 2 was further divided into: (a) Gestational hypertension $(\mathrm{n}=130)$. (b) Mild preeclampsia $(n=21)$. (c) Severe preeclampsia $(n=40)$. (d) Eclampsia $(n=11)$.

\section{Inclusion criteria}

- $\quad$ Single intrauterine pregnancy

- Pregnant women diagnosed with hypertension at gestation $\geq 20$ weeks.

\section{Exclusion criteria}

- History of medical disorders like chronic hypertension, diabetes mellitus, heart disease, liver disease, renal disease, thyroid disorder, epilepsy and hemolytic anaemia

- Trauma, bone fracture and muscle injury.

Subjects were also divided according to the serum LDH levels into following groups:

- $\mathrm{LDH}<600 \mathrm{IU} / \mathrm{L}$

- $\mathrm{LDH}-600-800 \mathrm{IU} / \mathrm{L}$

- $\mathrm{LDH}>800 \mathrm{IU} / \mathrm{L}$
All the pregnant women with blood pressure $\geq 140 / 90$ $\mathrm{mmHg}$ were evaluated in the study group along with consecutive number of age and parity matched normotensive control group. On admission, detailed history including menstrual history, obstetric history and history of hypertension was taken. Period of gestation was calculated from last menstrual period/ first trimester/ early second trimester fetal biometry. Complete general physical examination, systemic examination, obstetric examination per abdomen, per vaginum was done as per performa. Patient admitted with hypertension were monitored during their stay in hospital and antepartum complication if any were recorded. All investigation routine and specific to PIH including LDH was done. Patients were followed till delivery. Before the termination of pregnancy LDH levels was estimated in both the groups. Plain blood sample of about $2 \mathrm{ml}$ was collected for analysis of LDH which was done in fully automated biochemistry analyser AU680; Beckman Coulter. Labour was managed partographically and mode of delivery was noted. Post-partum complication if any was recorded during stay in Hospital. Neonatal parameter noted included live birth/still birth, Apgar score at 1 and 5 minutes, birth weight, sign of meconium aspiration, admission in NICU and total duration of stay in NICU was recorded. The fetomaternal outcome in the study and control group was compared.

\section{Statistical analysis}

Statistical difference between two groups was evaluated using chi square test with epi info 7 . The $p$ value of $<0.05$ was considered as statistically significant.

\section{RESULTS}

A total of 404 women were included in the study out of which 202 were normotensive controls and 202 study subjects. Those in the study group comprised of gestational hypertension (130), mild pre-eclampsia (21), severe preeclampsia (40) and eclampsia (11).

Table 1: Relation of LDH with different group.

\begin{tabular}{|c|c|c|}
\hline Group & $\begin{array}{l}\text { LDH level } \\
(\text { mean+SD) }\end{array}$ & p value \\
\hline Control $(n=202)$ & $234.19 \pm 176.62$ & \multirow{5}{*}{$\begin{array}{l}\mathrm{p}=<0.001 \\
\text { highly } \\
\text { significant }\end{array}$} \\
\hline GEST HNT $(n=130)$ & $364.43 \pm 212.61$ & \\
\hline Mild PET $(n=21)$ & $473.14 \pm 212.57$ & \\
\hline Severe PET $(n=40)$ & $646.32 \pm 212.61$ & \\
\hline Eclampsia $(n=11)$ & $822.36 \pm 212.61$ & \\
\hline
\end{tabular}

The mean age of subjects in gestational hypertension, mild PET, severe PET and eclampsia was 27.23 \pm 2.64 , $27.31 \pm 2.64,27.08 \pm 2.62$ and $24.08 \pm 2.16$ years.

It was observed that $94.05 \%$ subjects were booked in control group and $83.66 \%$ in study group. Maximum number of subjects, $98.51 \%$ were from rural area in 
control group whereas in study group $91.58 \%$ were from rural areas.

Table 1 shows the relation of LDH level with the severity of the disease. It was noted that in the control group all had levels of $<600 \mathrm{U} / \mathrm{L}$ and mean value of $\mathrm{LDH}$ was $234.19 \pm 176.62$ IU/L. In women with gestational hypotension mean value of LDH was $364.43 \pm 178.048$ IU/L. In mild preeclampsia mean LDH level was $473.14 \pm 212.57 \mathrm{IU} / \mathrm{L}$ and in severe preeclampsia mean LDH level was 646.32 $\pm 212.61 \mathrm{IU} / \mathrm{L}$. In eclampsia mean LDH level was $822.36 \pm 212.61 \mathrm{U} / \mathrm{L}$.
This is due to more hemolysis and liver damage at higher blood pressure (ANOVA F=58.09 p=0.001) highly significant.

Table 2 shows the relation between LDH levels and the various symptoms in the study.

Women with LDH concentration $>800$ IU/L had a significantly higher frequency of headache. It was observed that at LDH level $<600,600-800$ and $>800 \mathrm{IU} / \mathrm{L}$ headache was present in $12(3.23 \%), 6(33.33 \%)$ and 7 $(46.67 \%)$ subjects respectively.

Table 2: Symptoms according to the level of LDH.

\begin{tabular}{|lllll|}
\hline Symptoms & LDH $<600(n=371)$ & LDH 600-800 $(\mathbf{n}=\mathbf{1 8})$ & LDH $>$ 800 $(\mathbf{n}=\mathbf{1 5})$ & $\mathrm{p}$ value \\
\hline Headache & $12(3.23 \%)$ & $6(33.33 \%)$ & $7(46.67 \%)$ & $\mathrm{p}=<0.001$ \\
\hline Epigastric pain & $10(2.69 \%)$ & $6(33.33 \%)$ & $6(40 \%)$ & $\mathrm{p}=<0.001$ \\
\hline Vomiting & $10(2.69 \%)$ & $6(33.33 \%)$ & $6(40 \%)$ & $\mathrm{p}=<0.001$ \\
\hline Blurred vision & $10(2.69 \%)$ & $6(33.33 \%)$ & $6(40 \%)$ & $\mathrm{p}=<0.001$ \\
\hline
\end{tabular}

Values in percentages.

Table 3: LDH level with maternal outcome.

\begin{tabular}{|lllll|}
\hline \multirow{2}{*}{$\begin{array}{l}\text { Maternal complications } \\
\text { Antepartum }\end{array}$} & $\mathbf{6 6 0 0}(\mathbf{n}=\mathbf{3 7 1})$ & $\mathbf{6 0 0 - 8 0 0}(\mathbf{n = 1 8})$ & $\mathbf{> 8 0 0}(\mathbf{n}=\mathbf{1 5})$ & $\mathrm{p}$ value \\
\hline HELLP syndrome & $1(0.27 \%)$ & $1(5.55 \%)$ & $3(20 \%)$ & $\mathrm{p}=<0.001$ \\
\hline Abruption & $0(\%)$ & $2(11.11 \%)$ & $3(20 \%)$ & $\mathrm{p}=<0.001$ \\
\hline Thrombocytopenia & $0(\%)$ & $1(5.55 \%)$ & $0(\%)$ & $\mathrm{p}=0.37$ \\
\hline Intrapartum & & & & \\
\hline Pulmonary oedema & $0(\%)$ & $0(\%)$ & $3(20.00 \%)$ & $\mathrm{p}=<0.001$ \\
\hline Renal failure & $0(\%)$ & $0(\%)$ & $1(6.67 \%)$ & $\mathrm{p}=<0.001$ \\
\hline Post-partum & & & $2(13.33 \%)$ & $\mathrm{p}=<0.001$ \\
\hline Atonic PPH & $1(0.27 \%)$ & $2(11.11 \%)$ & $0(\%)$ & $\mathrm{p}=0.14$ \\
\hline Postpartum LSCS hysterectomy & $1(0.27 \%)$ & $0(\%)$ & $1(6.67 \%)$ & $\mathrm{p}=<0.001$ \\
\hline Maternal mortality & $0(\%)$ & $1(5.55 \%)$ & & \\
\hline Values in percentage & & & & \\
\hline
\end{tabular}

Epigastric pain and vomiting were also observed in significantly higher number of women with $\mathrm{LDH}>800$ U/L. It was observed that at LDH level <600, 600-800 and $>800 \mathrm{IU} / \mathrm{L}$ epigastric pain was observed $10(2.69 \%)$, $6(33.33 \%)$ and $6(40 \%)$ of subjects respectively. It was also observed that at LDH level <600, 600-800 and >800 IU/L vomiting was observed in 10 (2.69\%), $6(33.33 \%)$ and $6(40 \%)$ of subjects respectively. LDH level $<600$, $600-800 \mathrm{IU} / \mathrm{L}$ and $>800 \mathrm{IU} / \mathrm{L}$ blurring of vision was observed in $10(2.69 \%), 6(33.33 \%)$ and $6(40 \%)$ subjects respectively. Thus, patients with $\mathrm{LDH}$ concentration $>800 \mathrm{IU} / \mathrm{L}$ had a significant increase in the frequency of blurring.

Table 3 shows the various maternal complications. During antepartum period, HELLP syndrome occurred in
$20 \%$ subjects at $\mathrm{LDH}$ level $>800 \mathrm{IU} / \mathrm{L}$ as compared to $5.5 \%$ at levels $600-800 \mathrm{U} / \mathrm{L}$. Maximum number of abruption occurred at LDH level >800 IU/L in $3(20 \%)$ subjects and $2(11.11 \%)$ cases of abruption occurred at LDH level between 600-800 IU/L. In the intrapartum period, $20 \%$ subjects developed pulmonary oedema. And $6.67 \%$ subject developed acute renal failure at LDH level $>800 \mathrm{IU} / \mathrm{L}$. During postpartum period a total of 5 (24.71\%) subjects developed PPH. Out of these 5, 2 (13.33\%) developed PPH at level >800 IU/L, $2(11.11 \%)$ at $600-800 \mathrm{IU} / \mathrm{L}$ whereas $1(0.27 \%)$ had $\mathrm{PPH}$ at $<600$ IU/L). 1 woman $(0.27 \%)$ underwent caesarean hysterectomy to control the bleeding. Maternal mortality was observed in two subjects, $1(5.55 \%)$ at $\mathrm{LDH}$ level between $600-800 \mathrm{IU} / \mathrm{L}$ and $1(6.67 \%)$ at $\mathrm{LDH}$ level $>800$ IU/L. 
Perinatal outcome in relation to $\mathrm{LDH}$ levels is depicted in Table 4. The mean gestational age at delivery, birth weight and Apgar were significantly less in those with
LDH >800 IU/L. When the LDH was >800 U/L, still births and neonatal deaths were significantly increased as compared to those with $\mathrm{LDH}<800 \mathrm{U} / \mathrm{L}$.

Table 4: LDH level with perinatal outcome.

\begin{tabular}{|lllll|} 
& $\begin{array}{l}\text { LDH level } \\
<600 ~ I U / L\end{array}$ & $\begin{array}{l}\text { LDH level } \\
\mathbf{6 0 0 - 8 0 0 ~ I U / L}\end{array}$ & $\begin{array}{l}\text { LDH level } \\
>\mathbf{8 0 0} \text { IU/L }\end{array}$ & $\mathrm{p}$ value \\
\hline Mean gestation age in (weeks) & $38.07 \pm 1.11$ & $34.87 \pm 2.44$ & $33.27 \pm 0.70$ & $\mathrm{p}=<0.001$ \\
\hline Mean birth weight in (grams) & $2,480.10 \pm 0.64$ & $18,88.88 \pm 0.64$ & $1630 \pm 0.64$ & $\mathrm{p}=<0.001$ \\
\hline Apgar at 1 min & $6.68 \pm 1.81$ & $4.5 \pm 1.89$ & $2.46 \pm 1.89$ & $\mathrm{p}=<0.001$ \\
\hline Apgar at 5 min & $8.62 \pm 2.37$ & $5.94 \pm 2.37$ & $3.26 \pm 2.37$ & $\mathrm{p}=<0.001$ \\
\hline Still birth & $13(3.50 \%)$ & $5(27.27 \%)$ & $9(60 \%)$ & $\mathrm{p}=<0.001$ \\
\hline Neonatal death & $2(0.53 \%)$ & $2(11.11 \%)$ & $3(20 \%)$ & $\mathrm{p}=<0.001$ \\
\hline
\end{tabular}

NICU: Neonatal intensive care unit. Values are given as mean SD and percentages.

\section{DISCUSSION}

Hypertensive disorders of pregnancy are known since ancient time. In spite of many recent advances, the exact pathology of the disease is not known. Many theories have suggested that endothelial dysfunction caused by factor released from ischemic placenta may be a causative factor for disease pathogenesis. In this study, authors found significantly elevated level of serum LDH in women with sever pre-eclampsia and eclampsia as compared with control. These findings were in accordance with the study conducted by Qublan $\mathrm{H}$ et al, and Kozic $\mathrm{J}$ et al. ${ }^{6,7}$ The symptoms and occurrence of complications correlated with the levels of $\mathrm{LDH}$. The multiorgan dysfunction in severe pre-eclampsia caused by vascular endothelial damage, including maternal liver, kidney, lungs nervous system, blood and coagulation system, will lead to excessive LDH leakage and elevated levels in serum due to cellular dysfunction. Serum LDH can be useful marker for prediction of adverse outcome of pregnancy in severe pre-eclampsia. Severe preeclampsia has also found to be useful predictor for birth of small for gestational age infants in pre-eclamptic pregnancy. ${ }^{6}$ The hypertensive disorders are also associated with complications such as HEELP syndrome, thrombocytopenia, acute renal failure, pulmonary oedema and maternal mortality. HEELP syndrome is mnemonic if the syndrome characterized by hemolysis, elevated liver enzyme and low platelet count. In hypertensive disorders of pregnancy, activation of the compliment and coagulation cascades, increased vascular tone, platelet aggregation, and alteration of the thromboxane prostacyclin ratio etc. events are present. The lead to systemic endothelial and microvascular injury and causing microangiopathic hemolytic anemia, periportal hepatic necrosis, and thrombocytopenia, thus leading to HEELP syndrome. RBC and hepatocytes contain good amount of LDH enzyme, elevated levels of serum LDH may signify the presence of hemolysis and hepatic cell death. ${ }^{2}$ Perinatal mortality increased significantly with
LDH level >800 IU/L. Increased risk of adverse fetal outcome in patients with elevated liver enzymes was also observed in a study conducted by Sibai et al. ${ }^{8}$ Young age and prim gravidity are the well-known risk factors for the development of preeclampsia. ${ }^{9}$ In the present study, women with severe preeclampsia and eclampsia were significantly younger and with low gravidity and parity compared with normotensive controls and mild preeclamptic women. In our study, mean birth weight of babies born to severe preeclamptic mothers was found significantly low as compared to normotensive controls. ${ }^{7,10}$ Epigastric pain or right upper quadrant pain is often a symptom of severe preeclampsia and may be caused by subcapsular hematoma, abnormal liver function in HEELP syndrome due to periportal hemorrhagic necrosis or it may be indicative of imminent eclampsia. In most of the cases the symptom is associated with headache, blurred vision or vomiting. ${ }^{11}$ In this study, mean gestational age at the time of delivery was less in patients with increasing LDH levels. This indicate increase in preterm and IUGR deliveries. ${ }^{12}$

Therefore, estimation of serum LDH at regular interval may give insight to ongoing disease progression and organ damage. It may prove to be a useful tool to predict the maternal and fetal complications even at an earlier stage of the disease.

\section{CONCLUSION}

Regular estimation of LDH is advisable for pregnancy diagnosed with hypertensive disorders in order to detect and prevent the morbidity and mortality in mother and in fetus. It may give an idea regarding the disease severity and functioning of liver and kidney. Progressive increase in LDH level should be considered a signal for intervention to improve pregnancy outcome.

Thus, large randomized control trials are required to make LDH level as an important parameter to help in 
making decision regarding the management strategies to improve maternal and fetal outcome.

\section{ACKNOWLEDGMENTS}

Authors would like to thank all those who helped for comparison and for all the references.

Funding: No funding sources Conflict of interest: None declared

Ethical approval: The study was approved by the Institutional Ethics Committee

\section{REFERENCES}

1. Park K. Textbook of Preventive medicine in obstetrics, pediatrics and geriatrics, $21^{\text {st }}$ ed. Textbook of preventive and social medicine. Banarsidas Bhanot publishers Jabalpur (M.P.) India; 2011: 481-560.

2. Sonagra AD, Dattatreya K, Murthy JDS. Serum. LDH, ALP and uric acid in hypertensive disorders of pregnancy. Int J Pharm Biol Sci. 2012;2(3):201-9.

3. Nosrat BS, Azarhoosh R, Borghei A, Sedaghati M, Besharat S, Ghaemi E. Serum level of lactate dehydrogenase, homocysteine, hemoglobin and platelet in preeclampsia. Pak J Med Sci. 2011;27(5):1014-7.

4. Islam NAF, Chowdhury MAR, Kibria GM, Akhter S. Study of serum lipid profile in pre-eclampsia and eclampsia. Faridpur Med Coll J. 2010;5(2):56-9.

5. Abbassi-Ghanavati M, Geer LG, Cunningham FG. Pregnancy and laboratory studies: a reference table for clinicians. Obstet Gynecol. 2009;114(6):1326-31.

6. Qublan HS, Ammarin V, Bataineh O, Al-Shraideh Z, Tahet Y, Awamleh I, et al. Lactate dehydrogenase as a biocjemical marker of adverse pregnancy outcome in severe pre-eclampsia. Med Sci Monit. 2005;11(8):393-7.

7. Kozic J, Benton S, Hutcheson J, Payne B, Magee L, Dadelszen P. Abnormal liver function tests as predictors of adverse maternal outcome in women with preeclampsia. J Obstet Gynecol Can. 2011;33(10):995-1004 .

8. Sibai BM. Diagnosis and management of gestational hypertension and preeclampsia. Am J Obstet Gynecol. 2003;102(1):181-92.

9. Munde SM, Hazari NR, Thorat AP, Gaikwad SB, Hatolkar VS. Gamma glutamyl transferase and lactate dehydrogenase as biochemical markers of severity of preeclampsia. Int $\mathrm{J}$ Med Health Biomed Bioengineer Pharma Engineer. 2014;8(1):50-3.

10. Minakami H, Sato T, Takahashi T, Oka N, Tamada T. Clinical significance of sGOT elevation and thrombocytopenia in preeclampsia patients. Nihon Sanka Fujinka Gakkai Zasshi. 1988;40(6):754-60.

11. Norwitz ER Hsu CD, Repke JT. Acute complications of preeclampsia. Clin Obstet Gynecol. 2002;45:30829.

12. Sreelatha S, Bharathi A, Ramya S, Sharau S. Estimation of serum LDH and uric acid in preeclampsia and its correlation with maternal and perinatal outcome. Int $\mathrm{J}$ Adv Case Reports. 2015;2(7):447-9.

Cite this article as: Kumar A, Pathania K, Kandoria M. Evaluation of serum lactate dehydrogenase in hypertensive disorders of pregnancy and its comparison with normal pregnancy. Int J Reprod Contracept Obstet Gynecol 2020;9:3270-4. 